DOI: $10.14451 / 1.189 .55$

\title{
МЕТОДИЧЕСКИЙ ПОДХОД К УПРАВЛЕНИЮ СТРАТЕГИЧЕСКИМИ РИСКАМИ В УСЛОВИЯХ ВЫСОКОЙ РЫНОЧНОЙ ВОЛАТИЛЬНОСТИ
}

(C) 2020 Михайловский Д. А.

Санкт-Петербургский университет технологий управления и экономики, Россия, Санкт-Петербург

Высокие темпы развития современных цифровых технологий создают потребность в решении ряда задач по формированию и интеграции новых систем управления бизнес-процессами. В статье предложена концепция и формализован механизм управления стратегическими рисками торговых предпринимательских структур. Разработаны и представлены методы снижения негативного результата за счет локализации и абсорбирования воздействия риска на бизнес-процессы торговой структуры, определены методы управления, децентрализованной СУР. Структурирован механизм контроля и управления задачами в рамках СУР, детализирующий основные принципы системы управления стратегическими рисками. Применительно к торговому предпринимательству материалы статьи дают риск-менеджерам необходимый инструментарий для автоматизации процесса риск-менеджмента с использованием современных цифровых технологий.

Ключевые слова: торговое предпринимательство, предпринимательская структура, рискменеджмент, сквозное управление.

\section{Введение}

Цифровизация экономики диктует предпринимателям новые условия для формирования бизнес-моделей, заставляя разрабатывать новые инструменты, позволяющие оптимизировать бизнес-процессы, таргетировать предложения и рекламу, создавать новые продукты и новые рынки в рамках растущего спроса на цифровые технологии. При этом инновационный процесс порождает новые предпринимательские риски, управление которыми является важным критерием успешной предпринимательской деятельности в современных экономических условиях.

В научных трудах, посвященных проблематике управления рисками большинство авторов сходятся во мнении, что система управления рисками является важным инструментом в управлении предпринимательской структуры и должна быть интегрирована в общую систему менеджмента. Кроме того, управление рисками должно учитывать взаимное воздействие рисков и обеспечивать своевременную идентификацию факторов риска, в системе должна осуществляться корректировка методов и инструментов управления [1-5].

Вместе с тем, необходимо обратить внимание на то, что развитие современных цифровых технологий даёт возможность пересмотреть процесс управления рисками в рамках новой парадигмы, ориентированной на децентрализацию бизнес-процессов [6]. По мнению автора, данный аспект исследований методов управления рисками является недостаточно изученным и является фактором новизны настоящей статьи.

В настоящей статье представлен методический подход управления стратегическими рисками предпринимательской структуры, основанный на систематизации управленческих решений, подчиненных разработанным правилам и инструкциям, также объединяющий различные степени воздействия рисков и являющийся основой для создания и интеграции в систему управления компании автоматизированной, децентрализованной системы риск-менеджмента.

\section{Методология и теория}

Стремительные темпы развития НТП формируют определенные тенденции в экономике, политике, обществе, которые меняют сложившийся ранее уклад. Сформированные на глобальном уровне тенденции, за счет высокой степени экономической и социальной интеграции, быстро распространяются на национальном уровне, формируя новый ландшафт предпринимательских рисков. Таким образом, возникает сквозное воздействие различных видов рисков, сформированных на глобальном уровне, непосредственно на предпринимательские структуры в определенных территориальных экономических экосистемах [7].

Предлагаемая автором система управления стратегическими рисками обеспечивает опе- 
ративное принятие управленческих решений в зависимости от сложившейся рыночной конъектуры.

В процессе управления стратегическими рисками предпринимательской структуры установлено шесть режимов управления в зависимости от уровня прибыли или убытков относительно точки безубыточности:

1-й режим - Уровень прибыли более 30\%

2-й режим - Уровень прибыли 20-30\%

3-й режим - Размер прибыли до $20 \%$

4-й режим - Размер убытков до 25\%

5-й режим - Уровень убытков от 25 до 50\%

6-й режим - Размер убытков более 50\%

Система управления рисками подчиняет себе все бизнес-процессы, проходящие внутри компании. Управление этими процессами осуществляется в соответствии с пакетом инструкций, имеющим свой номер и относящимся к определенному режиму управления, который, в свою очередь, регламентируется уровнем прибыли. Каждый пакет инструкций определяет регламент осуществления бизнес-процессов каждого подразделения на период действия данного пакета и предписывает выполнение ряда задач, в рамках которых достигается цель определенного режима управления СУР.

Режим управления определяется процентным отношением прибыли или убытков к точке безубыточности - Точка 0 (Т0). В качестве генеральной цели СУР устанавливается значение прибыли $30 \%$ от Т0.

\section{1-й режим управления}

Применяется в условиях, когда уровень прибыли составляет более $30 \%$ от Т0. Основной целью СУР в данном режиме является обеспечение ликвидности товарного ассортимента. В данном режиме работает пакет инструкций 11 , в рамках которого подразделения компании выполняют задачи по расширению рынков сбыта, инвестиции в новые проекты, создание резервов и т.д.

\section{2-й режим управления}

При снижении уровня прибыли в диапазон 20-30\% вступает в силу режим № 2. Целью СУР в данном режиме является обеспечение ликвидности товарного ассортимента и повышение уровня прибыли до 30\% от Т0.

Динамика движения уровня дохода в системе управления стратегическими рисками является важным индикатором, определяющим открытие того или иного номера пакета инструкций. При изменении направленности - с падающей на нейтральную или на восходящую выполняется переход от одного пакета инструкций к другому, который будет отвечать соответствующим изменениям и регламентировать действия подразделений в соответствии с новыми вводными. В этих условиях при снижении объемов продаж открывается пакет инструкций 211, при нейтральной динамике - пакет 212, при росте объемов продаж - пакет инструкций 213, рамках которых осуществляется работа над ранее запущенными проектами, создание резервов и т.д. При этом в условиях нейтральной и отрицательной динамики объемов продаж - не желательны инвестиции в новые проекты.

\section{3-й режим управления}

Режим управления № 3 вступает в силу при воздействии рисков, приведших к снижению прибыли ниже 20\% от Т0. При этом возникают риски возникновения убытков. Еще одним параметром, указывающим на открытие номера пакета, является интервал времени, в течение которого прибыль компании находится на определенном уровне. При воздействии краткосрочных рисков длительностью до 3мес, в зависимости от динамики объемов продаж, управление компанией осуществляется в соответствии с инструкциями 311, 312, 313, предписывающих работу над запущенными ранее проектами и создание резервов. При воздействии среднесрочных рисков длительностью от 3 до 9 мес. в зависимости от динамики объемов продаж выполняются инструкции 321, 322, 323. Воздействие долгосрочных рисков сроком более 9 мес., не позволяющих повысить уровень прибыли выполняются инструкции 331, 332, 333. В рамках, которых необходимо выполнение задач по снижению расходов, оптимизации товарной линейки и т.д.

\section{4-й режим управления}

Режим управления № 4 определяет управление стратегическими рисками в условиях образовавшихся убытков до 25\% от Т0. Основной целью управления в данном режиме является обеспечение точки безубыточности Т0 хозяйственной деятельности.

В данном режиме приходится временно отказаться от генеральной цели, выдвинув в качестве главной цели - обеспечение Точки 0. Следует отметить, что в соответствии с настоящей системой управления стратегическими рисками при длительном периоде существования убытков до 25\%, с отрицательной или нейтральной 
динамикой роста доходов и воздействия долгосрочных частных рисков - следует рассмотреть вариант изменения существующей бизнесмодели. Это решение подразумевает, что на протяжении 9 месяцев, компания предпринимала усилия по снижению расходов, управлению частными рисками, оптимизируя при этом товарный ассортимент, политику продаж, штат сотрудников, площади и т.д. При этом все мероприятия, призванные оздоровить ситуацию и выйти на целевые показатели, были безуспешны. В условиях положительной динамики роста объемов продаж, решение о радикальном изменении бизнес-модели следует отложить, так как в результате роста доходов возникают предпосылки, что существующая бизнес-модель еще не исчерпала себя и имеется возможность оздоровления ситуации.

В данном режиме при воздействии краткосрочных рисков реализуются пакеты инструкций 411,412 , 413, в рамках которых выполняются задачи по оптимизации штата сотрудников, товарной линейки, открытие кредитных линий, общее снижение расходов компании, изменение политики продаж. Воздействие среднесрочных рисков от 3 до 6 мес. будет являться основанием для запуска пакета инструкций 421, 422, 423 согласно которым, кроме вышеперечисленных задач, требуется задействовать резервы для покрытия кассового разрыва. При воздействии долгосрочных рисков сроком более 9 мес. должны быть запущены пакеты инструкций 431, 432, 433. Здесь дополнительно выполняются задачи по оптимизации торговых площадей, ликвидации отдельных подразделений и т.д. При отсутствии роста прибыли от хозяйственной деятельности сроком более 9 мес. является основанием для пересмотра существующей бизнес- модели.

\section{5-й режим управления}

В данном режиме основной целью СУР является снижение расходов и обеспечение точки безубыточности. В данном режиме предпринимательская структура испытывает воздействие частных рисков, имеющих высокие параметры, или происходит одновременное воздействие двух и более рисков. В условиях краткосрочного воздействия рисков сроком до 3 мес. в зависимости от динамики объемов продаж задействуются пакеты инструкций 511, 512, 513, предписывающие выполнение задач по оптимизации торговых площадей, штата сотрудников и т.д.
Среднесрочное снижение прибыли в данном режиме сроком 3-9мес. означает запуск пакетов инструкций $521,522,523$, в рамках которых дополнительно осуществляется открытие кредитных линий, изменение политики продаж и т.д. При воздействии долгосрочных рисков 6-9 мес выполняются инструкции 531, 532, 533, предписывающие более радикальное изменение в системе управления, вплоть до изменения бизнесмодели.

\section{6-й режим управления}

Режим управления СУР при росте убытков от предпринимательской деятельности выше уровня 50\% от Т0. Целью СУР в данном режиме является обеспечение точки безубыточности в рамках общего снижения расходов компании и изменения модели управления.

При воздействии краткосрочных рисков управление осуществляется в соответствии с пакетами инструкций 611, 612, 613 в зависимости от динамики объемов продаж. При снижении прибыли в соответствии с данным режимом сроком от 3 до 6 мес. выполняются инструкции 621, 622, 623, которые предусматривают выполнение задач по оптимизации торговых площадей, штата сотрудников, изменение политики продаж и т.д. Воздействие долгосрочных рисков с периодом более 9 мес. является основанием для изменения существующей бизнес-модели, либо ухода предпринимательской структуры с данного сегмента рынка.

При формализации процедуры управления стратегическими рисками на каждом уровне следует придерживаться следующих базовых принципов:

1. Принции перманентности, в соответствии с которым сквозное управление рисками должно представлять собой непрерывный процесс, характеризующийся последовательным непрерывным применением методов и инструментов риск - менеджмента в хозяйственной деятельности субъекта предпринимательства с учётом опыта их предшествующего применения на каждой из стадий существования рисков.

2. Принциип обратной связи, в соответствии с которым должна осуществляться корректировка методов и инструментов управления рисками по результатам анализа и оценки эффективности применяемых методов и инструментов.

3. Принцип учёта взаимного влияния рисков, в соответствии с которым управление рисками 
Таблица 1. Режимы управления стратегическими рисками (разработано автором)

\begin{tabular}{|c|c|c|c|c|c|c|}
\hline $\begin{array}{l}\text { период } \\
\text { воздей }\end{array}$ & \multicolumn{2}{|c|}{$\begin{array}{c}\text { отрицательная динамика объемов } \\
\text { продаж }\end{array}$} & \multicolumn{2}{|c|}{$\begin{array}{c}\text { нейтральная динамика объемов } \\
\text { продаж }\end{array}$} & \multicolumn{2}{|c|}{$\begin{array}{c}\text { положительная динамика объемов } \\
\text { продаж }\end{array}$} \\
\hline $\begin{array}{c}\text { рисков } \\
\text { (мес) }\end{array}$ & $\begin{array}{l}\text { пакет } \\
\text { инстр }\end{array}$ & основные Vektor-задачи & $\begin{array}{l}\text { пакет } \\
\text { инстр }\end{array}$ & основные Vektor-задачи & $\begin{array}{l}\text { пакет } \\
\text { инстр }\end{array}$ & основные Vektor-задачи \\
\hline \multicolumn{7}{|c|}{1 й режим Уровень прибыли более 30\% } \\
\hline & \multicolumn{6}{|c|}{ При любой динамике объемов продаж применяется пакет инструкций №11 } \\
\hline & & вные Vektor-задачи пакета 11 & оасшире & ие рынков сбыта, инвестициь & новые г & оекты, создание резервов \\
\hline \multicolumn{7}{|c|}{ 2-й режим Уровень прибыли 20-30\% } \\
\hline \multirow{3}{*}{$\begin{array}{l}\text { более } \\
6\end{array}$} & \multirow{3}{*}{21} & $\begin{array}{l}\text { реализация запущенных } \\
\text { проектов }\end{array}$ & \multirow[t]{3}{*}{ 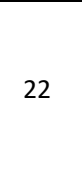 } & $\begin{array}{l}\text { реализация запущенных } \\
\text { проектов }\end{array}$ & \multirow{3}{*}{23} & $\begin{array}{l}\text { реализация запущенных } \\
\text { проектов }\end{array}$ \\
\hline & & создание резервов & & создание резервов & & создание резервов \\
\hline & & $\begin{array}{l}\text { не желательны новые } \\
\text { инвестиции }\end{array}$ & & $\begin{array}{l}\text { не желательны новые } \\
\text { инвестиции }\end{array}$ & & \\
\hline \multicolumn{7}{|c|}{ 3-й режим Уровень прибыли до 20\% } \\
\hline \multirow{3}{*}{ до 3} & \multirow{3}{*}{311} & $\begin{array}{l}\text { реализация запущенных } \\
\text { проектов }\end{array}$ & \multirow{3}{*}{312} & $\begin{array}{l}\text { реализация запущенных } \\
\text { проектов }\end{array}$ & \multirow{3}{*}{313} & $\begin{array}{l}\text { реализация запущенных } \\
\text { проектов }\end{array}$ \\
\hline & & создание резервов & & создание резервов & & создание резервов \\
\hline & & $\begin{array}{l}\text { не желательны новые } \\
\text { инвестиции }\end{array}$ & & $\begin{array}{l}\text { не желательны новые } \\
\text { инвестиции }\end{array}$ & & \\
\hline \multirow{3}{*}{$\begin{array}{c}\text { от } 3 \text { до } \\
9\end{array}$} & \multirow{3}{*}{321} & $\begin{array}{l}\text { реализация запущенных } \\
\text { проектов }\end{array}$ & \multirow{3}{*}{322} & $\begin{array}{l}\text { реализация запущенных } \\
\text { проектов }\end{array}$ & \multirow{3}{*}{323} & $\begin{array}{l}\text { реализация запущенных } \\
\text { проектов }\end{array}$ \\
\hline & & создание резервов & & создание резервов & & создание резервов \\
\hline & & $\begin{array}{l}\text { не желательны новые } \\
\text { инвестиции }\end{array}$ & & $\begin{array}{l}\text { не желательны новые } \\
\text { инвестиции }\end{array}$ & & $\begin{array}{l}\text { не желательны новые } \\
\text { инвестиции }\end{array}$ \\
\hline \multirow{4}{*}{$\begin{array}{c}\text { более } \\
9\end{array}$} & \multirow{4}{*}{331} & снижение расходов & \multirow{4}{*}{332} & снижение расходов & \multirow{4}{*}{333} & $\begin{array}{l}\text { оптимизация товарной } \\
\text { линейки }\end{array}$ \\
\hline & & $\begin{array}{l}\text { оптимизация товарной } \\
\text { линейки }\end{array}$ & & $\begin{array}{l}\text { оптимизация товарной } \\
\text { линейки }\end{array}$ & & $\begin{array}{l}\text { приостановка новых } \\
\text { проектов }\end{array}$ \\
\hline & & $\begin{array}{l}\text { приостановка новых } \\
\text { проектов }\end{array}$ & & $\begin{array}{l}\text { приостановка новых } \\
\text { проектов }\end{array}$ & & \\
\hline & & оптимизация штата & & & & \\
\hline & & & јежим & ровень убытков до 25\% & & \\
\hline \multirow{6}{*}{ до 3} & \multirow{6}{*}{411} & $\begin{array}{l}\text { реализация запущенных } \\
\text { проектов }\end{array}$ & \multirow{6}{*}{412} & $\begin{array}{l}\text { реализация запущенных } \\
\text { проектов }\end{array}$ & \multirow{6}{*}{413} & $\begin{array}{l}\text { реализация запущенных } \\
\text { проектов }\end{array}$ \\
\hline & & оптимизация штата & & $\begin{array}{l}\text { открытие новых кредитных } \\
\text { линий }\end{array}$ & & $\begin{array}{l}\text { открытие новых кредитных } \\
\text { линий }\end{array}$ \\
\hline & & $\begin{array}{l}\text { открытие новых кредитных } \\
\text { линий }\end{array}$ & & $\begin{array}{l}\text { оптимизация товарной } \\
\text { линейки }\end{array}$ & & $\begin{array}{l}\text { оптимизация политики } \\
\text { продаж }\end{array}$ \\
\hline & & $\begin{array}{l}\text { оптимизация товарной } \\
\text { линейки }\end{array}$ & & $\begin{array}{l}\text { оптимизация политики } \\
\text { продаж }\end{array}$ & & $\begin{array}{l}\text { приостановка новых } \\
\text { инвестиций }\end{array}$ \\
\hline & & $\begin{array}{l}\text { оптимизация политики } \\
\text { продаж }\end{array}$ & & $\begin{array}{l}\text { приостановка новых } \\
\text { инвестиций }\end{array}$ & & \\
\hline & & $\begin{array}{l}\text { приостановка новых } \\
\text { инвестиций }\end{array}$ & & & & \\
\hline \multirow{7}{*}{$\begin{array}{c}\text { от } 3 \text { до } \\
9\end{array}$} & & $\begin{array}{l}\text { реализация запущенных } \\
\text { проектов }\end{array}$ & & $\begin{array}{l}\text { реализация запущенных } \\
\text { проектов }\end{array}$ & & $\begin{array}{l}\text { приостановка новых } \\
\text { инвестиций }\end{array}$ \\
\hline & & оптимизация штата & & оптимизация штата & & оптимизация штата \\
\hline & & $\begin{array}{l}\text { открытие новых кредитных } \\
\text { линий }\end{array}$ & & $\begin{array}{l}\text { открытие новых кредитных } \\
\text { линий }\end{array}$ & & $\begin{array}{l}\text { открытие новых кредитных } \\
\text { линий }\end{array}$ \\
\hline & 421 & $\begin{array}{l}\text { оптимизация товарной } \\
\text { линейки }\end{array}$ & 422 & $\begin{array}{l}\text { оптимизация товарной } \\
\text { линейки }\end{array}$ & 423 & задействование резервов \\
\hline & & $\begin{array}{l}\text { оптимизация политики } \\
\text { продаж }\end{array}$ & & $\begin{array}{l}\text { оптимизация политики } \\
\text { продаж }\end{array}$ & & \\
\hline & & $\begin{array}{l}\text { приостановка новых } \\
\text { инвестиций }\end{array}$ & & $\begin{array}{l}\text { приостановка новых } \\
\text { инвестиций }\end{array}$ & & \\
\hline & & задействование резервов & & задействование резервов & & \\
\hline $\begin{array}{l}\text { более } \\
9 \text { мес }\end{array}$ & & & & очных рисков - изменен & $C N$ & ели \\
\hline
\end{tabular}




\begin{tabular}{|c|c|c|c|c|c|c|}
\hline \multicolumn{7}{|c|}{ 5-й режим Уровень убытков 25-50\% } \\
\hline \multirow{6}{*}{ до 3} & \multirow{6}{*}{511} & снижение расходов & \multirow{6}{*}{512} & $\begin{array}{l}\text { реализация запущенных } \\
\text { проектов }\end{array}$ & \multirow{6}{*}{513} & $\begin{array}{l}\text { реализация запущенных } \\
\text { проектов }\end{array}$ \\
\hline & & оптимизация штата & & $\begin{array}{l}\text { открытие новых кредитных } \\
\text { линий }\end{array}$ & & $\begin{array}{l}\text { открытие новых кредитных } \\
\text { линий }\end{array}$ \\
\hline & & $\begin{array}{l}\text { открытие новых кредитных } \\
\text { линий }\end{array}$ & & $\begin{array}{l}\text { оптимизация товарной } \\
\text { линейки }\end{array}$ & & $\begin{array}{l}\text { оптимизация политики } \\
\text { продаж }\end{array}$ \\
\hline & & $\begin{array}{l}\text { оптимизация товарной } \\
\text { линейки }\end{array}$ & & $\begin{array}{l}\text { оптимизация политики } \\
\text { продаж }\end{array}$ & & $\begin{array}{l}\text { приостановка новых } \\
\text { инвестиций }\end{array}$ \\
\hline & & $\begin{array}{l}\text { оптимизация политики } \\
\text { продаж }\end{array}$ & & $\begin{array}{l}\text { приостановка новых } \\
\text { инвестиций }\end{array}$ & & \\
\hline & & $\begin{array}{l}\text { приостановка новых } \\
\text { инвестиций }\end{array}$ & & & & \\
\hline \multirow{8}{*}{$\begin{array}{c}\text { от до } \\
9\end{array}$} & \multirow{8}{*}{521} & $\begin{array}{l}\text { реализация запущенных } \\
\text { проектов }\end{array}$ & \multirow{8}{*}{522} & $\begin{array}{l}\text { реализация запущенных } \\
\text { проектов }\end{array}$ & \multirow{8}{*}{533} & $\begin{array}{l}\text { приостановка новых } \\
\text { инвестиций }\end{array}$ \\
\hline & & оптимизация штата & & оптимизация штата & & оптимизация штата \\
\hline & & $\begin{array}{l}\text { открытие новых кредитных } \\
\text { линий }\end{array}$ & & $\begin{array}{l}\text { открытие новых кредитных } \\
\text { линий }\end{array}$ & & $\begin{array}{l}\text { открытие новых кредитных } \\
\text { линий }\end{array}$ \\
\hline & & $\begin{array}{l}\text { оптимизация товарной } \\
\text { линейки }\end{array}$ & & $\begin{array}{l}\text { оптимизация товарной } \\
\text { линейки }\end{array}$ & & задействование резервов \\
\hline & & изменение политики продаж & & $\begin{array}{l}\text { изменение политики } \\
\text { продаж }\end{array}$ & & оптимизация площадей \\
\hline & & оптимизация площадей & & отказ от новых инвестиций & & \\
\hline & & задействование резервов & & задействование резервов & & \\
\hline & & $\begin{array}{l}\text { оптимизация } \\
\text { подразделений }\end{array}$ & & $\begin{array}{l}\text { оптимизация } \\
\text { подразделений }\end{array}$ & & \\
\hline $\begin{array}{c}\text { более } \\
9\end{array}$ & \multicolumn{6}{|c|}{ при воздействии долгосрочных рисков - изменение бизнес модели } \\
\hline \multicolumn{7}{|c|}{ 6-й режим Уровень убытков 25-50\% } \\
\hline \multirow{6}{*}{ до 3} & \multirow{6}{*}{611} & снижение расходов & \multirow{6}{*}{612} & $\begin{array}{l}\text { реализация запущенных } \\
\text { проектов }\end{array}$ & \multirow{6}{*}{613} & $\begin{array}{l}\text { реализация запущенных } \\
\text { проектов }\end{array}$ \\
\hline & & оптимизация штата & & $\begin{array}{l}\text { открытие новых кредитных } \\
\text { линий }\end{array}$ & & $\begin{array}{l}\text { открытие новых кредитных } \\
\text { линий }\end{array}$ \\
\hline & & $\begin{array}{l}\text { открытие новых кредитных } \\
\text { линий }\end{array}$ & & $\begin{array}{l}\text { оптимизация товарной } \\
\text { линейки }\end{array}$ & & $\begin{array}{l}\text { оптимизация политики } \\
\text { продаж }\end{array}$ \\
\hline & & $\begin{array}{l}\text { оптимизация товарной } \\
\text { линейки }\end{array}$ & & $\begin{array}{l}\text { оптимизация политики } \\
\text { продаж }\end{array}$ & & $\begin{array}{l}\text { приостановка новых } \\
\text { инвестиций }\end{array}$ \\
\hline & & $\begin{array}{l}\text { оптимизация политики } \\
\text { продаж }\end{array}$ & & отказ от новых инвестиций & & \\
\hline & & отказ от новых инвестиций & & оптимизация штата & & \\
\hline \multirow{8}{*}{$\begin{array}{c}\text { от } 3 \text { до } \\
9\end{array}$} & \multirow{8}{*}{621} & $\begin{array}{l}\text { приостановка запущенных } \\
\text { проектов }\end{array}$ & \multirow{8}{*}{622} & $\begin{array}{l}\text { реализация запущенных } \\
\text { проектов }\end{array}$ & \multirow{8}{*}{633} & $\begin{array}{l}\text { приостановка новых } \\
\text { инвестиций }\end{array}$ \\
\hline & & оптимизация штата & & оптимизация штата & & оптимизация штата \\
\hline & & $\begin{array}{l}\text { открытие новых кредитных } \\
\text { линий }\end{array}$ & & $\begin{array}{l}\text { открытие новых кредитных } \\
\text { линий }\end{array}$ & & $\begin{array}{l}\text { открытие новых кредитных } \\
\text { линий }\end{array}$ \\
\hline & & $\begin{array}{l}\text { оптимизация товарной } \\
\text { линейки }\end{array}$ & & $\begin{array}{l}\text { оптимизация товарной } \\
\text { линейки }\end{array}$ & & задействование резервов \\
\hline & & изменение политики продаж & & $\begin{array}{l}\text { изменение политики } \\
\text { продаж }\end{array}$ & & оптимизация площадей \\
\hline & & оптимизация площадей & & отказ от новых инвестиций & & $\begin{array}{l}\text { оптимизация товарной } \\
\text { линейки }\end{array}$ \\
\hline & & задействование резервов & & задействование резервов & & $\begin{array}{l}\text { изменение политики } \\
\text { продаж }\end{array}$ \\
\hline & & $\begin{array}{l}\text { оптимизация } \\
\text { подразделений }\end{array}$ & & $\begin{array}{l}\text { оптимизация } \\
\text { подразделений }\end{array}$ & & \\
\hline $\begin{array}{c}\text { более } \\
9\end{array}$ & & & & олгосрочных рисков - ухо & ка & \\
\hline
\end{tabular}


должно учитывать взаимное воздействие рисков и обеспечивать своевременную идентификацию предвестников и факторов риска.

4. Принциип интеграции, в соответствии с которым система управления рисками должна быть интегрирована в общую систему менеджмента предприятия [8].

5. Принции эффективности. Риск-менеджмент создает и защищает стоимость Компании. Целью управления рисками является обеспечение устойчивого конкурентоспособного развития бизнеса за счет снижения непредвиденных расходов, защиты репутации предпринимательской структуры, формирующей лояльность потребителей и влияющую на объемы продаж. Все мероприятия по управлению рисками должны быть экономически обоснованы и не превышать по стоимости ожидаемый ущерб от активации рисков.

6. Принции ответственности. Ответственность за риски означает наличие всесторонней, полностью определенной и принятой ответственности за активацию и негативные последствия рисков, как со стороны управленческих структур, так и отдельных работников [9].

7. Принции полноты используемой информации. В процессе риск-менеджмента принимается во внимание вся доступная информация, включая данные из сети Интернет, которые могут быть аккумулированы ботами [10,11].

В управление рисками вовлечены все подразделения предпринимательской структуры. Генеральная ответственность за принимаемые решения лежит непосредственно на предпринимателе.

Оперативное управление осуществляет управляющий риск-менеджер, который входит в совет по рискам, состоящий, как правило, из руководителей подразделений и отдельных специалистов. В обязанности совета входит:

1. Определение критериев риска;

2. Определение лиц, ответственных за разработку, внедрение и поддержание инфраструктуры риск-менеджмента;

3. Определение критериев эффективности риск-менеджмента;

4. Рассмотрение результатов мониторинга риск-менеджмента;

5. Оценка эффективности СУР.

6. Совету подчинен комитет по рискам, в состав которого входят все руководители отделов.

\section{Разработка пакетов инструкций}

Система управления стратегическими рисками может быть адаптирована под любую торговую организацию. При ее построении следует иметь представление о существующей локальной рыночной экосистеме, резервах компании, людском потенциале. В процессе управления трезвая и холодная оценка в положительной ситуации позволит оптимизировать доходы, а в кризисной ситуации позволит существенно ограничить убытки. Пакет инструкций разрабатывается на основе основных принципов управления каждого уровня и содержит ряд задач, обеспечивающих достижение цели управления СУР в определенном режиме для определенного подразделения.

Для контроля режимов системы управления рисками автором предлагается применение опережающего индикатора целевого значения СУР.

Данный индикатор является главным инструментом в системе управления стратегическими и частными рисками в период проведения постактивационных мероприятий, а также прогнозирования целевого значения в условиях воздействия некоторых частных рисков с известными временными параметрами. Индикатор сигнализирует об изменении уровня прибыли, что является целевым показателем СУР.

В комплексе с показателем роста объемов продаж, индикатор подает сигнал об изменение режима управления стратегическими рисками и открытия определенного пакета инструкций.

В этот момент начинается постактивационный этап в системе управления частных рисков, в рамках которого осуществляется управление риском в момент его воздействия. Снижение целевого показателя означает об активации частных рисков, воздействие которых привело к снижению прибыли.

Совокупная степень воздействия этих рисков отражается на графике в виде снижения целевого показателя. Чем больше временной показатель частных рисков, тем больший период времени будет наблюдаться отклонение графика от заданной цели, что будет способствовать принятию решения об изменении пакета инструкций.

Снижение целевого значения с одновременным сокращением объемов продаж, как правило, осуществляется под воздействием частных 
Таблица 2. Пример разработки пакета инструкций в системе управления стратегическими рисками (разработано автором)

\begin{tabular}{|c|c|}
\hline \multicolumn{2}{|c|}{ пакет инструкций 522} \\
\hline Юридический отдел & сокращение штата $10 \%$ \\
\hline Бухгалтерия & сокращение штата $10 \%$ \\
\hline \multirow{3}{*}{ Отдел логистики } & оптимизация логистических цепочек \\
\hline & поиск отсрочки платежей \\
\hline & сокращение штата $10 \%$ \\
\hline \multirow{3}{*}{ Отдел продаж } & оптимизация товарной линейки \\
\hline & оптимизация площадей \\
\hline & сокращение штата $10 \%$ \\
\hline \multirow{2}{*}{ Отдел Маркетинга } & разработка акционных программ \\
\hline & поиск новых товаров и услуг \\
\hline \multirow{2}{*}{ Отдел рекламы } & разработка компаний распродаж \\
\hline & сокращение штата 10\% \\
\hline \multirow{2}{*}{ Отдел кадры } & оптимизация штата сотрудников организации \\
\hline & сокращение штата $10 \%$ \\
\hline \multirow{3}{*}{ Финансовый директор } & поиск источников финансирования \\
\hline & ужесточение бюджетной дисциплины \\
\hline & устранение кассового разрыва \\
\hline \multirow{2}{*}{ Склад } & оптимизация площадей \\
\hline & сокращение штата $10 \%$ \\
\hline Отдел закупок & поиск товарных кредитов \\
\hline Служба безопасности & ужесточение внутреннего контроля \\
\hline Сис. администрация & штатный режим \\
\hline
\end{tabular}




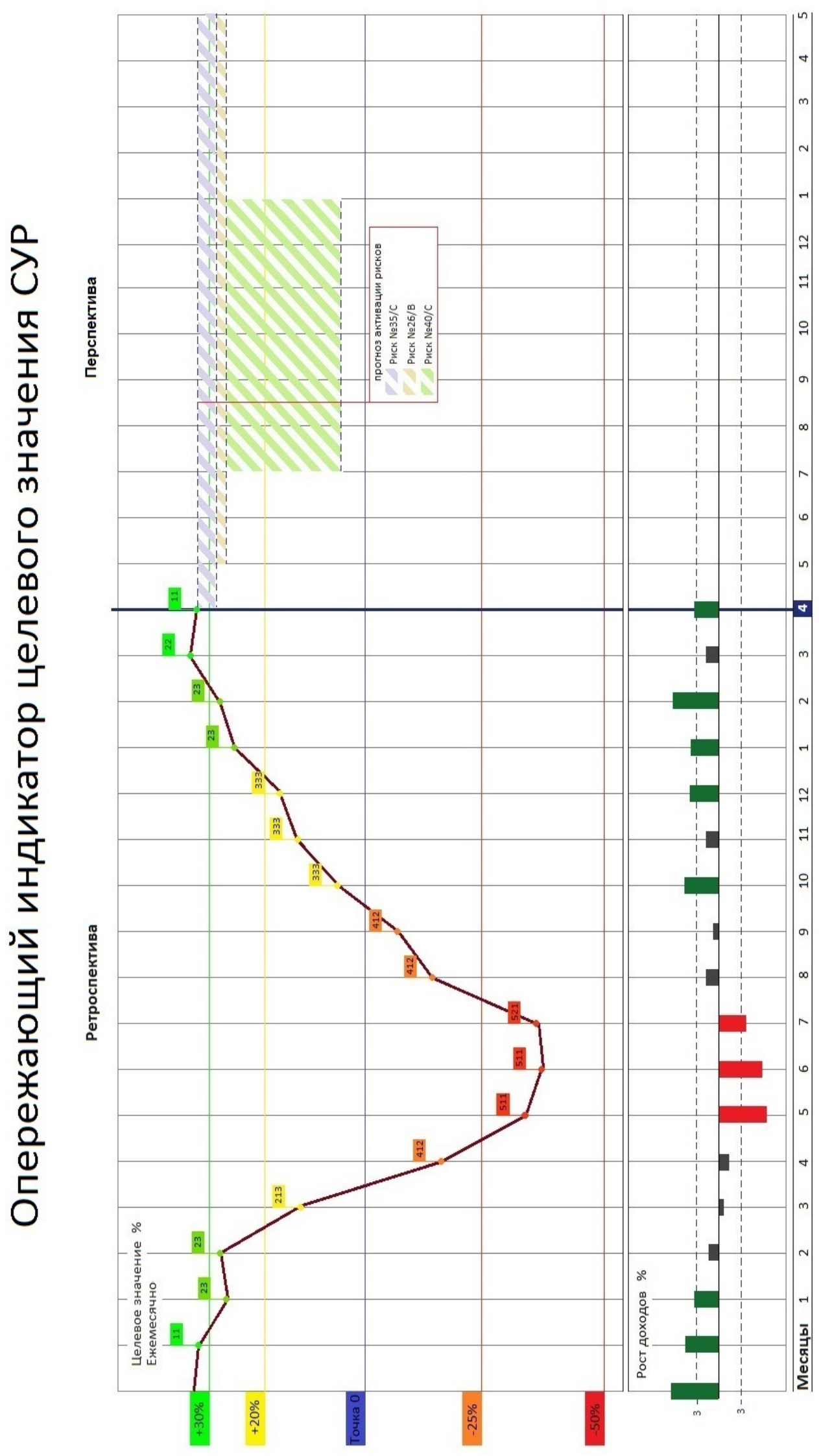

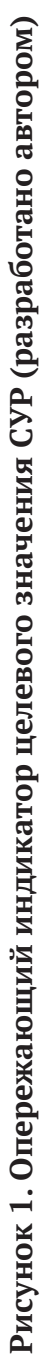


рисков, имеющих высокий показатель значимости. Такое снижение обязывает открытие пакетов инструкций, предписывающих системные изменения в зависимости от режима управления. Рост индикатора объемов продаж в период длительного отклонения целевого значения от целевого уровня служит сигналом к возможному выходу из кризисной ситуации, что предписывает открытие очередного пакета инструкций в соответствии с системой управления стратегическими рисками.

В правом окне графика «перспектива» отражаются риски, при оценке которых были определены все параметры, в том числе и временные. Прогнозируемая величина риска и период воздействия устанавливаются в уровне текущего целевого значения, и отражают область вероятного отклонения целевого значения.

Сигналы индикатора обеспечивают:

1. Определение отклонения значения прибыли от целевого;

2. Определение режима управления и номера пакета инструкций в соответствии с системой управления стратегическими рисками;

3. Прогнозирование окончания периода воздействия частных рисков;

4. Определение вероятного отклонения целевого значение СУР.

\section{Выводы:}

В условиях бурного развития современных цифровых технологий и автоматизации бизнеспроцессов важным критерием эффективности риск-менеджмента является оперативность и систематизация принимаемых решений. Применение концепции управления стратегическими рисками позволяет своевременно реагировать на рост предпринимательских рисков, и изменять основные критерии управления предпринимательской структурой.

Интеграция системы управления стратегическими рисками повышает эффективность менеджмента компании в кризисных условиях, усиливая устойчивость к стрессовым ситуациям и повышая порог рентабельности.

Методика принятия решения позволяет минимизировать субъективность оценки существующей экономической ситуации со стороны риск-менеджера, что обеспечивает своевременность и точность принимаемых управленческих решений.

Опережающий индикатор целевого значения СУР является эффективным инструментом риск-менеджмента, обеспечивающим оперативность принятия управленческих решений в условия высокой рыночной волатильности и возрастающих предпринимательских рисков.

\section{Библиографический список}

1. Кунин В.А. Управление рисками промышленного предпринимательства (теория, методология, практика).СПб.: Изд-во Санкт-Петербургской академии управления и экономики, 2011.- С.25.

2. Zemtsov S., Barinova V., Semenova R. (2019) The Risks of Digitalization and the Adaptation of Regional Labor Markets in Russia. Foresight and STI Governance, vol. 13, no 2, pp. 84-96. DOI: 10.17323/2500-2597.2019.2.84.96

3. Бургонов О.В., Голубецкая Н.П., Смешко О.Г. Влияние цифровых технологий на развитие системы управления предпринимательскими структурами. Проблемы современной экономики.- СПб, № 1(73) 2020 - С.65.

4. Кунин В.А. Превентивное управление предпринимательскими рисками промышленных предприятий. СПб.: Изд-во Санкт-Петербургской академии управления и экономики, 2008.

5. Горохова Н.А. Управление налоговыми рисками как одно из значимых направлений корпоративного налогового менеджмента // Экономика. Налоги. Право. 2012. № 6. С. 77-81.

6. Шаланов Н. В. Математическая экономика.-Новосибирск: НГИ, 2005. - 259 с.

7. Федотова Г.В. Управление рисками в инновационной деятельности предприятий // Финансы и кредит. 2010. № 41 (425). C. 27-33. 